\title{
“The Giver" Film: a Concept of Environmental and Cultural Equality in Society
}

\author{
Al Farouq Lazuardo ${ }^{1{ }^{*}}$, M. Suryadi ${ }^{2}$ \\ ${ }^{1}$ Diponegoro University, English Literature Department, 50275 Semarang, Indonesia \\ ${ }^{2}$ Diponegoro University, Indonesian Literature Department, 50275 Semarang, Indonesia
}

\begin{abstract}
The Giver is a 2014 film adapted from a novel of the same name. The giver contains a supposition, which presupposes a world without war, racism, and discrimination. In this study, researchers used the theory of Multiculturalism from Clifford Geertz. The statement of this research is to know the condition if we live in such a perfect world without war, discrimination, racism. That exists in The Giver film and even in the current pandemic era. The data analysis in this study used a qualitative descriptive method. The results show that the true form of human perfection is our imperfection as humans themselves. When the elders in society in this film choose to create equations, throwing away human emotions and memories, they make a mistake. This conflict is a reflection of the absence of life with multiculturalism. Unlike film, we humans need emotions, and if we have emotions, we have to live in multiculturalism to avoid discrimination, racism, etc. Even during this pandemic, mutual respect for each other's differences makes life beautiful and colourful.
\end{abstract}

\section{Introduction}

At first, the film The Giver was a novel published in 1993 and adapted to a film in 2014 with the same title [1]. The Giver itself is a 2014 American romantic science-fiction drama film directed by Phillip Noyce and produced by Neil Koenigsberg and Nikki Silver. The script for this film was written by Michael Mitnick and Robert B. Weide based on Lois Lowry's novel The Giver [2]. The film begins at a time after the great disaster known as the Destruction, society is reorganized into a series of communities, and all past memories are held by one person, the Receiver of Memory. Since the Recipient of Memories is the only individual in the community with previous memories, he should advise the Chief Elder and other Elders about decisions over the community. Recipients of Memories are the only ones who have colour vision (colour blindness being a side effect of daily injections of emotionally paralyzing drugs that are put on other people).

\footnotetext{
"Corresponding author: alvarolazuardo@gmail.com
} 
Jonas is a 16-year-old teenager who is worried about the career he will assign like everyone else. His best friends are Asher and Fiona. On graduation day, each person is given a career according to what is happening in his life which has been monitored through cameras around the corner. Jonas was immediately ignored and not assigned to a career until the end of the ceremony when he was told that he would be the next Recipient of Memories and would receive memories from his predecessor, The Giver, who was previously named the Receiver of Memory.

During his training with The Giver, Jonas also learned about pain, love, and a variety of other emotions. After taking over the role that made him Recipient of Memories, Jonas learns from the past of The Giver and his daughter, Rosemary, who had preceded Jonas as Recipient of Memories. Rosemary is so desperate from the memory that she commits suicide, which the community considers "free". Its nature is considered mysterious, but the audience knows that it is death due to lethal injection. Jonas also found various facts, such as, for example, people who have been said to have left the community have actually been injected to death and that the recipient of his memories before him, Rosemary, decided to leave the community which was tantamount to being put to death. Jonas begins teaching Fiona his discoveries and decides to share ideas about emotions.

Fiona, who couldn't understand what emotion was, wasn't sure how she felt. Jonas then tells Fiona to stop taking the injections like he has been doing for the past month, and the next day, Jonas kisses Fiona, an ancient act that is unknown to the community, and Jonas gets it through Memories.

Jonas was very upset because his parents had tricked him. He felt that everyone should regain their memories and emotions. The Giver then gave him away to restore people's memories. However, Jonas had to cross the border and head for a place called Elsewhere. Jonas finally left after hearing the news that Gabe, a baby who was deemed "disabled" by the Care Center who was previously cared for by his family, would be sent to Elsewhere, which meant that the baby would be euthanized.

Based on the narrative regarding the elimination of the idea of emotion in this film, and the effect on the loss of colour vision, race, and religion, it is leading to the Concept of Environmental and Cultural Equality that is carried in this film, and that is what researchers will discuss in this study.

Islafatun [1] discusses the Giver but discusses what is contained in his novel, which is quite controversial because the characters are children in the novel. So the film makes a change about the main character which is now is a teenager.

\section{Proposed Method}

The method of analysis used in this paper is contextual literary analysis, focusing on the internal and external elements [3]. The internal elements that support the discussion are the characters plot/conflict and setting. The external element focuses on multiculturalism deducted by Geertz. The data gathered using the library method is analyzed through a descriptivequalitative method [4]..

\section{Result and Discussion}

It cannot be denied that the existence of a film is usually influenced by several famous novels, and eventually, it is made into a film that carries various lessons. The Giver also really raised various lessons, in this case, the moral and human aspects [5]. Jonas and The Giver 
characters here show that things like emotions, differences, feelings of love and love are beautiful things in our context as humans. The main characters in this film, Jonas and The Giver, also agree on this. Here are the results of the author's analysis of the film The Giver.

\subsection{Concept of Equality}

Whomever humans do not want to be differentiated, this is also raised in the film The Giver which carries this theme, namely when "if we live or live in the world with full equality". Instantly Jonas asked The Giver and there was a conversation like the following figure.

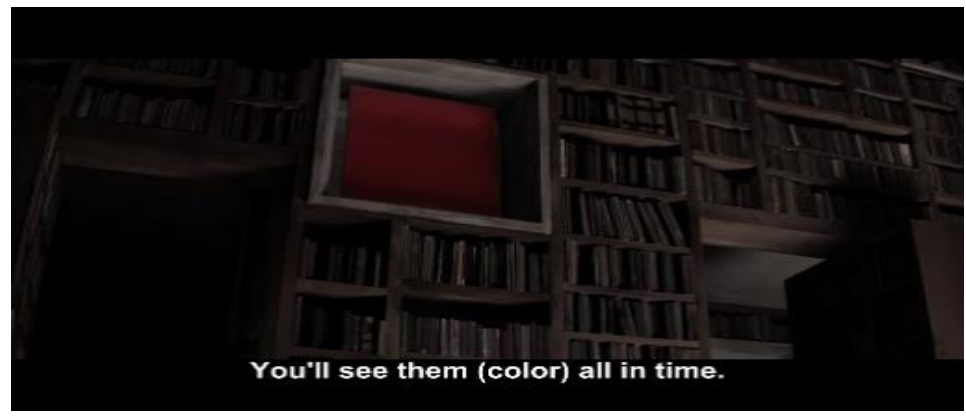

Fig. 1. Conversation about Equality The Giver and Jonas.

In In the conversation figure, it is explained that only The Giver and Jonas can see the colours and can see the difference. Jonas, who saw colour for the first time, was amazed at why this was eliminated in their community and thought differences were a beautiful thing.

In the case of this film, which raises the concept of equality without any differences, that a community is created in the film, which upholds equality and truth. This includes creating an equal residence and establishing rules such as: use precise language, wear your assigned clothes, take your morning medication, obey the curfew, and lastly, never lie. At a glance, you can imagine that we can live in safety without hate speech and then without differences and crime because there is a curfew and no lying. The regulations in the community will be discussed as follows:

\subsection{1 use precise language}

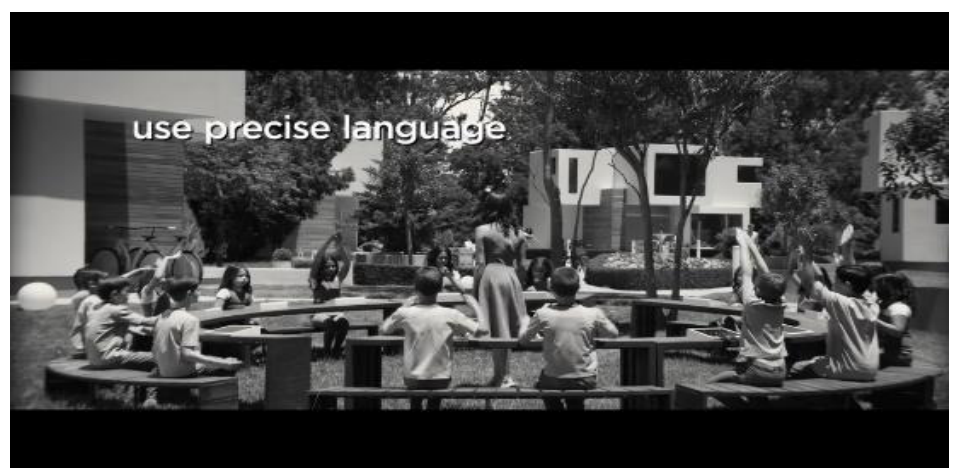

Fig. 2. Rule One in The Giver Film.

It is intended to prevent hate speech that will have an impact on mental health. It would be nice to use the right words so as not to hurt the feelings of others. 


\subsection{2 wear your assigned clothes}

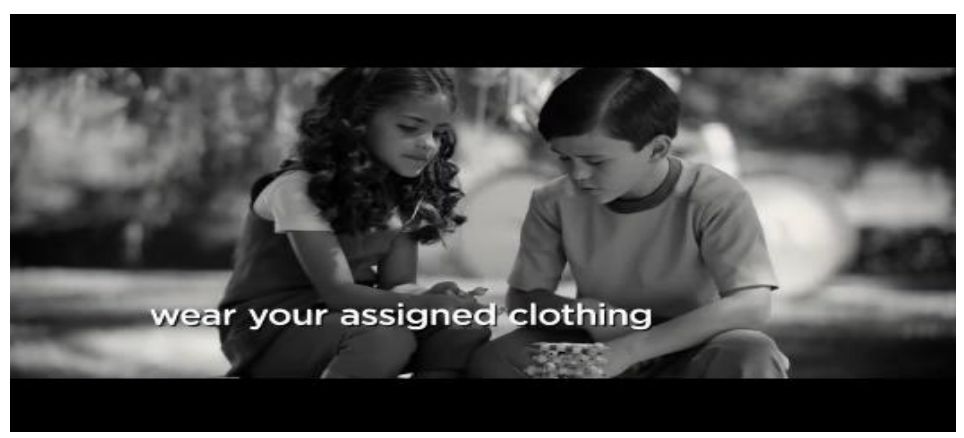

Fig. 3. Rule 2 in The Giver Film.

Intended to equalize people's opinions so that people are not jealous of them.

\subsection{3 take your morning medication}

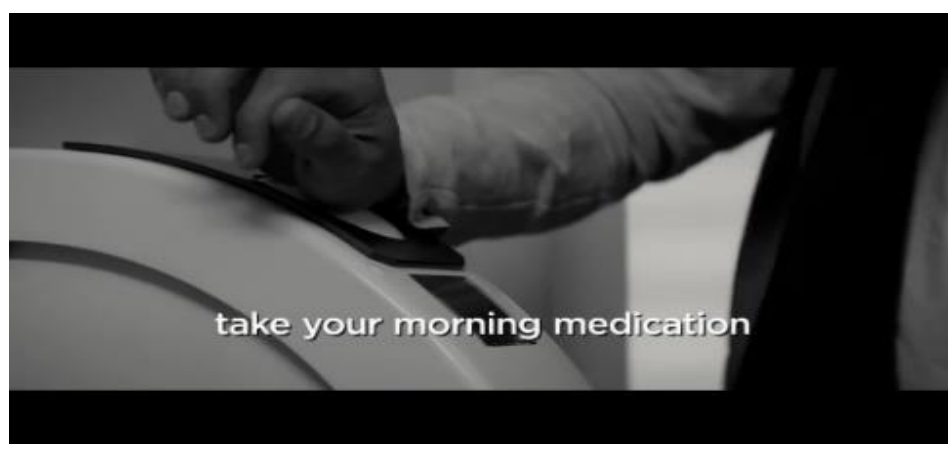

Fig. 4. Rule 3 in The Giver Film.

This morning's medicine is to erase emotions, emotions are the root of humans without human emotions will be more controlled and tend to be calm.

\subsection{4 obey the curfew}

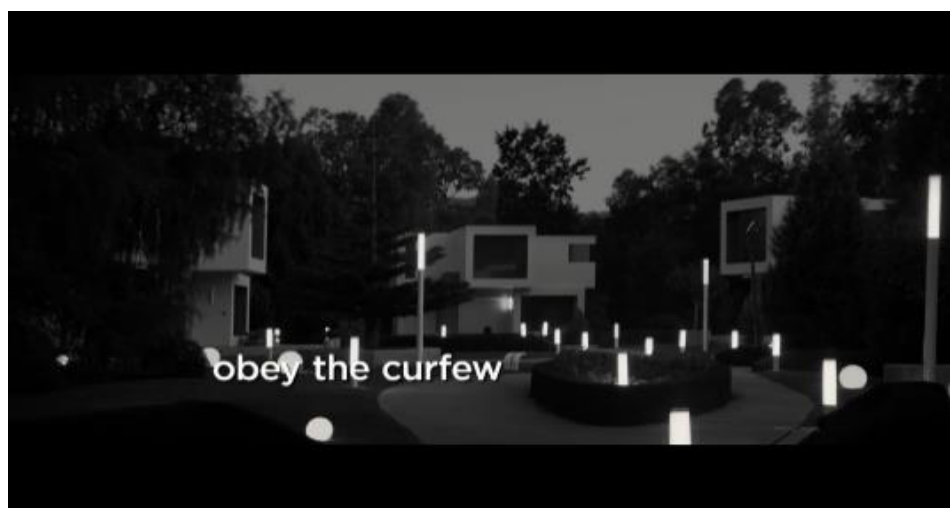

Fig. 5. Rule 4 in The Giver Film. 
Obeying the curfew allows us to sleep calmly and regularly and prevents unwanted things such as crimes that are usually committed at night.

\subsection{5 never lie}

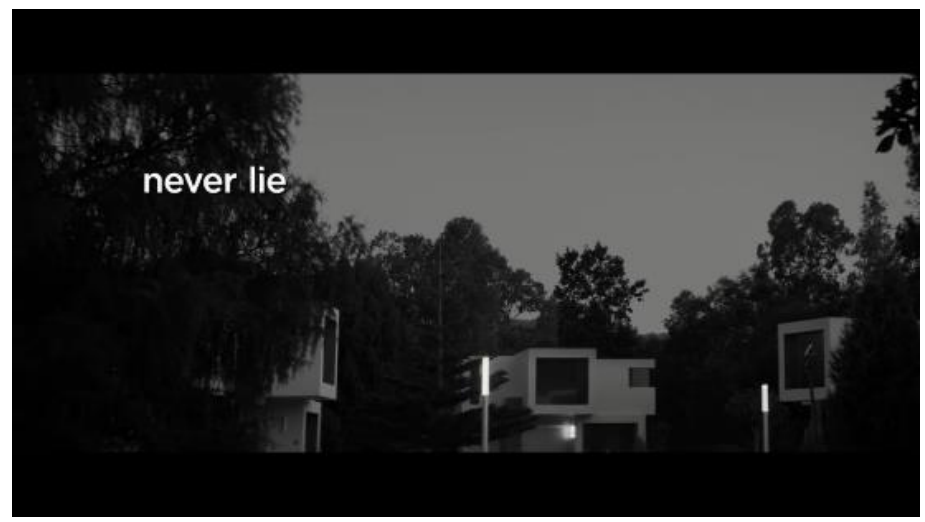

Fig. 4. Rule 5 in The Giver Film.

Lying is one of the causes of problems in humans, and this creates misunderstanding and makes people uneasy. It makes people feel curious.

All of these regulations are supported by the application of surveillance cameras on all sides of the community, and in the film, they are always monitored so that unwanted things do not happen. For example, the prohibition against holding hands with other people except with his own family unit. This can be seen from two sides, namely the positive and negative sides. On the positive side, this can prevent immoral and unkind things such as rape or theft by being friends. From a negative point of view, this can further dispel our emotions such as love and friendship, which require things like holding hands. For work problems, this film will be chosen by the elders based on the track record of their life until they are 16 years old. According to Zafir \& Fazilah, work is one of the sources of life problems and stress enhancers. If there are no work, stress increases, then cause us to be emotional and angry, blaming something, and at some point, it can lead to crime [2]. If you see the film, immediately get a job, there is no crime and only good things. It is a world that everyone longs for.

\subsection{Multiculturalism}

Based on the views shown by Clifford Geertz and also Ana Irhandayaningsih regarding Multiculturalism, namely Multiculturalism is an ideology as well as a means of creating peaceful relations between racial and cultural groups [7]. The fact that in Indonesia, my country is a very diverse nation is a fact that cannot be denied by anyone. Indonesia's diversity is not only reflected in the many islands united under one state control but also in the diversity of skin colours, languages, ethnicities, religions and cultures [8].

This means that we can accept each other's differences in skin colour, race and even religion so that we continue to have good and peaceful relationships without causing jealousy and jealousy because of differences [9]. In this film, The Giver reveals that the presence of emotions and memories, whether painful or fun, can change our lives. 


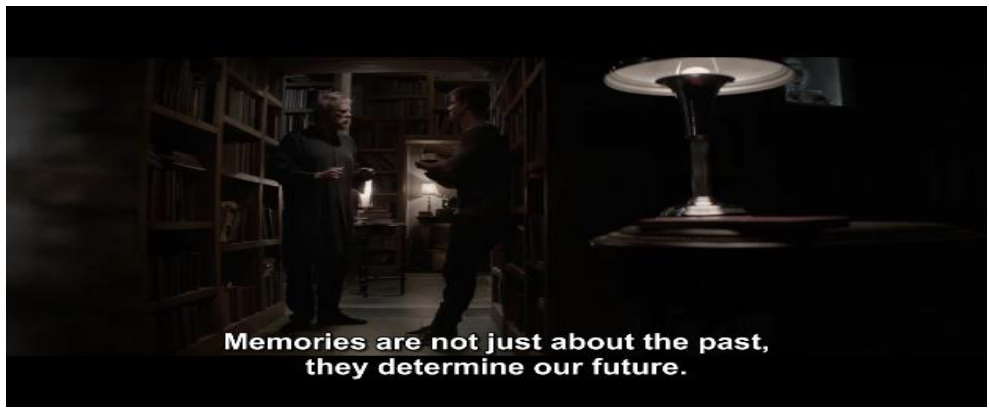

Fig. 6. Conversation between The Giver and Jonas.

$\mathrm{n}$ this film, the elimination of all memories from the past makes everything from the beginning of the past, as explained earlier, to make everything better without any memories, creating these five rules. And accidentally, there is "equality" in this film; whatever it is equalized for everything, including the building of the house, is the same. Then in this equality, newborns will enter "maturity selection", which is done by weighing them. For example, they do not meet the requirements that the baby will be sent to Elsewhere or other places, which means, in fact, they will be lethal injection. The elderly will also be sent to Elsewhere because they are too old.

Jonas and The Giver were furious to see this then decided to release the memories they had to everyone in the community by passing the Boundary of Memory or the Memory Limit; with this, Jonas and The Giver also shared Jonas' task towards the Limit of Memories, The giver was in charge of guiding people in the community so as not to get confused after the memories are released to everyone in the community. In this case, according to the author, equality is necessary, but how much more beautiful our lives would be if they were woven together by accepting differences between human beings, whether it be religion, race, politics and mutual respect among each other.

With mutual respect for differences, our lives will be filled with the colour of diversity; with emotions, we will find out what a composition, song, love, joy, feeling, and really means. But keep in mind that with full diversity, there will be envy, jealousy towards others, drowning in anger and any evil that arises from this character. How good it is that we can control our emotions with our religion and beliefs so that we avoid these negative human emotions [10].

\section{Conclusion}

Literary works that include emotions and expressions, such as films, have a significant role as a tool that can be used to change stigma or introduce new views. The view of a condition which, of course, is not necessarily in line with the prevailing construction of society. In connection with this opinion, the film The Giver for researchers explores views from all sides regarding the concept of equality and multiculturalism.

This can make a lesson, especially as a human being and as an Indonesian society, that living with differences is truly beautiful, especially during a pandemic like this when we consider that what we are going through now as "imperfect", and when we make it "perfect" according to what we want then there lies the "imperfection" where we want that we are "the same" which is if we are "different. "We can feel envy, anger, disrespect for each other and finally eliminate the colour, race, religion in this world which leads to the creation of" equality ". 
But in fact, eliminating all of that makes our emotions disappear, our life becomes monotonous. That is why what we consider "imperfect" is actually "perfection" possessed by humans who have emotions so that our lives will be more colourful and not monotonous. Cultural diversity in Indonesia is a prime example of living with multiculturalism, diverse races, religions, and colours are all so diverse in Indonesia, and we respect each other for that.

\section{References}

[1] N. Islafatun, "Pergeseran Peran Anak sebagai Agen Pengubah Struktur dalam Ekranisasi The Giver," Bul. Al-Turas, vol. 23, no. 2, pp. 301-318, 2017, doi: 10.15408/bat.v23i2.5821.

[2] J. Catarina, D. S. Caetano, and E. Morin, "Memories are Forever : Transhumanism and Cultural Memory in V for Vendetta , Oblivion and The Giver," Rev. Electrónica Estud. Anglo-Americanos, 2016.

[3] R. Asmarani, "The Transformations from the Novel Twilight by Stephenie Meyer to the Fan Fiction Master of the Universe by E.L. James,” 2019, doi: 10.2991/icille-18.2019.61.

[4] K. S. Lam, M. Lebl, and V. Krchňák, "The 'one-bead-one-compound' combinatorial library method," Chem. Rev., vol. 97, no. 2, pp. 411-448, 1997, doi: 10.1021/cr9600114.

[5] B. Weiner, D. Osborne, and U. Rudolph, "An attributional analysis of reactions to poverty: The political ideology of the giver and the perceived morality of the receiver," Personal. Soc. Psychol. Rev., vol. 15, no. 2, pp. 199-213, 2011, doi: $10.1177 / 1088868310387615$.

[6] M. Zafir and M. Fazilah, "Stres di tempat kerja dan kesannya terhadap keselamatan dan kesihatan pekerjaan,” J. Kesihat. Masy., 2006.

[7] Ana Irhandayaningsih, "Kajian Filosofis Terhadap Multikulturalisme Indonesia," J. Oasis, 2018.

[8] C. Geertz, "The Near East In The Far East: On Islam In Indonesia," Occas. Pap. Sch. Soc. Sci., 2001.

[9] C. Geertz, Ritual and Social Change: A Javanese Example, The Interp. New York: Basic Books, 1993.

[10] C. Geertz, Religion as Cultural System: In A Reader in Comparative Religion an Anthropological Approach, William A. New York: Harper and New Publisher, 1982. 